\section{A sociedade (e as pessoas) em movimento}

\author{
Eduardo Marandola Jr.*
}

\author{
KELLERMAN, Aharon. Personal \\ mobilities. London: Routledge, \\ 2006. 212p.
}

As transformações socioespaciais no mundo contemporâneo têm apresentado desafios maiores para os estudos populacionais. Compreender a dinâmica demográfica nestes tempos exige, cada vez mais, flexibilidade e abertura para novos olhares que ajudam a elucidar os processos contemporâneos.

No que tange à distribuição da população e sua espacialidade, nota-se um esforço grande por parte dos estudiosos para acompanhar esta sociedade que vive em constante movimento, em todos os sentidos. Desde os estudos migratórios, passando pela produção e organização espacial das cidades e regiões, a mobilidade adquire um papel central nos estudos populacionais, tornando-se um fenômeno à parte para ser pensado e analisado.

O livro do geógrafo Aharon Kellerman, Personal mobilities, é um capítulo deste esforço de tirar a mobilidade da simplificação à qual ficou restrita por tanto tempo, quando prevaleceu um olhar técnico (a dimensão estrutural-física) sobre o fenômeno. Guiado pela idéia de Lash e Urry, que afirmam que a "'modern society is a society on the move'" (KELERMANN, 2006, p.1), o autor procura entender a mobilidade para além destas questões, estabelecendo de forma mais clara um diálogo entre a dimensão física e a que chama de pessoal. Para isso, ele parte da idéia de que a mobilidade é um movimento individual, que inclui o corpo, as tecnologias de transporte (automóvel, estradas, transportes coletivos), além da mobilidade virtual, composta pelas novas tecnologias de comunicação (Internet, telefones, especialmente os móveis).

$\mathrm{Na}$ opinião do autor, as chamadas novas mobilidades são aquelas marcadas pela velocidade e virtualidade. $O$ fato novo desta mobilidade refere-se às possibilidades de aproximação e de convívio de pessoas com lugares, estabelecendo a simultaneidade dos tempos em espaços distantes. Mediando esta experiência nova, a escolha (controlada pelas possibilidades) permite a construção de mobilidades pessoais que interagem com a estrutura e com as tecnologias disponíveis nem sempre do mesmo modo entre pessoas que constituem os mesmos lugares ou grupos sociais. O livro está pautado na idéia de que as pessoas possuem liberdade e que há possibilidades e alternativas na sociedade contemporânea de constituição de seus caminhos e deslocamentos, dentro de um quadro delimitado, mas ainda assim múltiplo e variado.

$\mathrm{O}$ autor reclama uma abordagem geográfica que entenda a mobilidade para além de sua dimensão dos transportes, aproximando-se assim de uma pequena (mas significativa) bibliografia sociológica que procura examinar o modus operandi da lógica sociopolítica dos fluxos no espaço. Não se trata, no entanto, de uma transplantação da lógica de fluxos, mas sim de buscar a inter-relação entre as dimensões da mobilidade, as quais, para Kellerman (2006, p.4), são quatro: "people and societies, places and spaces, Technologies, and human activities." A estas, outras duas são acrescentadas como subcategorias: tempo e cultura (linguagem). A estrutura do livro busca desenvolver estas dimensões, encontrando nelas a base de compreensão das mobilidades pessoais no mundo contemporâneo.

São nove capítulos - incluindo a introdução e as conclusões -, que formam os elementos a partir dos quais Kellerman constrói sua perspectiva compreensiva das

\footnotetext{
* Geógrafo, pesquisador colaborador do Núcleo de Estudos de População, da Universidade Estadual de Campinas (Nepo/Unicamp).
} 
mobilidades pessoais, equilibrando estes elementos num diálogo bipolar da relação entre a estrutura-física e o corpo-virtualidade. As mobilidades ligadas ao transporte aéreo são vistas à parte, pois constituem elementos particulares de conexão entre os lugares e são vivenciadas por um pequeno número de pessoas (embora seja fundamental num olhar macroestrutural). Todos têm uma introdução e uma conclusão interna, o que vai somando ao argumento principal elementos que serão ponderados e discutidos no último capítulo. São eles:

\section{Introduction \\ 2. Individuals \\ 3. Society \\ 4. Technologies \\ 5. Nations \\ 6. Places \\ 7. Cities \\ 8. Flight \\ 9. Conclusion}

O autor levanta a importância da comunicação, colocando a questão: "If we can communicate freely from anywhere, and if we don't even have to care about the location of information (websites) that we access, could we assume a possible end of places?" (KELLERMAN, 2006, p.5). O livro dialoga com esta pergunta de fundo, procurando ponderar em que medida o elemento em tela de cada capítulo produz mobilidades pessoais específicas.

Ele propõe assim um entendimento da mobilidade pessoal a partir da relação en- tre motivos e atributos de mobilidade, que gera padrões de mobilidade (circulação e direção) de onde derivam componentes (estrutura-física) e condutores (experiências e relações sociais) (KELLERMAN, 2006, p.180)

Para tanto, cinco elementos são levados em consideração, os quais expressam o próprio sentido atribuído pelo autor às personal mobilities:

extensibility; access(ibility); speed; convenience; and fixity. Some of these elements may be approached and assessed as constituting both social values and geographical aspects in the facilitation and enhancement of personal motilities (speed, fixity and convenience), whereas others constitute social values and geographical aspects that affect moving people (extensibility and accessibility) (KELLERMAN, 2006, p.18).

A originalidade do livro, além de ampliar o escopo da discussão sobre mobilidade, está em seu quadro analítico de elementos de diferentes dimensões que permitem pensar a estruturação das cidades, os fluxos populacionais e sua distribuição no espaço. Se o autor reclama que a Geografia não tem dado a devida atenção às novas mobilidades, os estudos populacionais também estão devendo uma perspectiva mais abrangente que entenda a mobilidade em suas múltiplas dimensões e tipos.

Pensar as dimensões propostas por Kellerman pode ser um caminho para a construção de um pensamento demográfico

Recebido para publicação em 10/10/2008. Aceito para publicação em 14/11/2008. 